\title{
Family Functioning and Psychological Well-Being of Parents Raising Children with Hearing Impairment: A Case Study in Kericho County, Kenya
}

\author{
Nazarine Mbogo, Florence Githuthu (PhD), and Maria Ntaragwe \\ Department of Psychology, the Catholic University of Eastern Africa
}

\begin{abstract}
Hearing loss may lead to diverse consequences that affect an individual's quality of life. Parents with children who have any form of impairment bear the burden of providing effective care and support and this results to cases where they feel overwhelmed, disappointed and detached. The purpose of this study was to assess the family functioning on psychological well-being of parents raising children with hearing impairment in Kericho County, Kenya. The study was guided by the McMaster Model Family Functioning (MMFF) theory and it also reviewed the Family Systems theory and Olson Annular theory. Survey research design was used in the study. The target population of the study was $\mathbf{7 0 8}$ participants involving parents of children with hearing impairment and children with hearing impairment from Kericho County with a sample size 70 respondents including; parents and their children with hearing impairments. Data was collected using questionnaires. The findings of the study showed that communication patterns, affective responsiveness, problem-solving impacted on the wellbeing of participants. The study recommends that there should be common language for both the parents and children with hearing impairment in order to enhance effective communication hence parents to learn the Sign Language, to enable them communicate well with their children. The parents should learn how to express their affection to the child with hearing impairment and convey true feelings for their children with ease. Parents should involve children with hearing impairment in the problem solving process in issues that affect them directly. Parents should communicate the expected behaviour and be explicit about consequences that come along with non-compliance.
\end{abstract}

Key words: Psychological wellbeing, family functioning, hearing impairment.

\section{BACKGROUND}

$\mathrm{H}$ earing impairment, is a condition that has existed throughout human history. Hearing impairment is manifested when the child has partial or complete loss of hearing capability. This may be inherited or acquired through childhood infections such as otitis media, meningoencephalitis or malnourishment that may cause lack of Vitamin A and Iodine mineral (Cole, E. \&Flexer, 2019).

Hearing loss may lead to diverse consequences that affect an individual's quality life, such as the ability to hear, communicate and also the economic independence of the affected persons (Briffa, Davidson, \& Ferndale, 2016). Not only does hearing impairment affect the "self" but it also impacts heavily on the entire family, relations and community. Parents' stress is heightened by the increased need for child monitoring, support and financial implication (Seligman \& Darling, 2007). Hearing impairment is a hidden disability that is not easily observable. Its concealed nature makes it more challenging for parents to deal with as it impedes acceptability and provokes unsupportive reactions from majority of the extended family and community (Dyson, 2010; Seligman \& Darling, 2007).

Most of the parents (over 90\%) who give birth to children with hearing impairment are hearing parents. They continually experience a lot of psychosocial trauma because they have little or no knowledge, nor prior preparedness of raising a child who is hearing impaired (Kerenhappuch and Sridevi 2014; Humphries and Smith, 2019; Mweri, 2019). Parents of children with hearing impairments (PWCHI) require advice from professionals such as doctors to satisfy their anxiety. The doctors may as well be apprehensive about how to break the unpredicted results of the child's condition (Moeller, White \&Shisler, 2006). The doctor's advice or the manner in which they break the news may also have psychological effect on parents. Parents of children with hearing impairment are charged with the burden of providing effective care and support to the children. The excessive responsibility resulted to parents feeling overwhelmed, disappointed and isolated by the society. Parents of children with hearing impairment experience the desire for more emotional involvement and social support than parents of 'normal' children (Seligman \& Darling, 2007).

According to Zaidman-Zait (2014), parents raising children with hearing impairment experience high levels of parenting stress. This stress is related to challenges associated with experiences of raising a child with such impairment. This involves making decisions about medical care, education and communication. It is also a requirement for them to attend frequent medical and therapy appointments, learning to use and manage hearing devices and to manage the child's educational progress among many other services. The sum total of the difficulties faced by parents raising their hearing impaired children impedes the ability of the parents to support their children accordingly. It also causes difficulties related to interpersonal relationships with the child, spouse, and other 
family members including the professionals. Hence, such parents experience extreme levels of stress.

In Spain, a study was done in 2016 by SolaCarmona, Lopez-Liria, Padilla-Gongora, Daza and AguilarParra (2016). The findings indicate that, bringing up a disabled child may also produce exhaustion and tension between the parents due to arguments and less mutual understanding among family members in decision making. Changes in the family dynamics frequently occur as the members may feel doubtful about their abilities to care for their disabled child. This brings about symptoms of depression, anxiety and poor quality of life (Kuhlthau et al., 2010). A study conducted in South Carolina in USA to identify relationships between the unilateral and bilateral of a childhood hearing loss and presence of a cochlear implant(s) and the stress in hearing parents. The study reported that hearing parents of children with a cochlear implant(s) have the highest scores on all measures of stress except those measuring communication stresses. The study poses a relationship between family functioning and individual as well as family psychological well-being. When the family is dysfunctional there is a display of inability to cope up with needs and intentions that involve finding purpose in life, mastering ones environment, self-acceptance and positive interrelationship with other family members (Ryff, 2014).

In Romania in 2011 an investigation was done on the relationship between family functioning and coping capabilities in families with health difficulties. It indicated a positive correlation between family dysfunction and psychological symptoms. The study also noted a significant positive correlation between the coping strategies, passive appraisal and affective responsiveness. The study established frequent use of passive appraisal strategies is associated with high level of family dysfunction unlike affective responsiveness (Stanescu \& Romer, 2011).

Pozo, Sarriá and Brioso (2013) in their study on Family Quality of Life and Psychological wellbeing in parents of children with disability that, the severity of the disorder and social support play significant roles in coping strategies such as adaptation, active avoidance by male parents and constructive psychological well-being for mothers. The specific patterns of results for mothers and fathers contribute to comprehension of the psychological adaptation of parents. This could be taken into account in interventions with families.

A study was conducted in South Africa by John (2009) found the experiences of raising deaf children to be different depending on the family itself, school or the community it belongs. There are common notable experiences such as communication difficulties, financial difficulties, acceptability, stigmatization and strained interpersonal relationships. Other studies explored families in terms of wellbeing (Koen, Van Eeden \& Rothmann, 2013), family structure, life goals (Davids\& Roman, 2013), parenting
(Davids, Roman \& Leach, 2015) and healthy family functioning but not family structure or functioning effects on psychological need fulfilment in families with hearing impaired children (Davids, Ryan, Yassin, Hendrickse\& Roman, 2016; Zwane, Venter, Temane \& Chigeza, 2012).

A study in Kenya by Mweri, (2019) provides that $90 \%$ of children with hearing impairment are born and raised in hearing families. The children are not exposed to the privilege of acquiring Sign Language at the initial stage of language development and they do not enjoy the opportunity to communicate with family as hearing babies do. The absence of learning the first language of communication at the crucial age has a negative impact to both the child and the parents. The child experiences isolation, negligence in different forms while parents experience frustration of not knowing what to do with the child, how to express and respond to the needs of the child. Lack of communication with member family retards normal flow of family functioning hence Mweri, (2019) quoting from Seligman, (1984) says, a disability in one member of family, affects the entire system and eventually affects the person with impairment. Parents must accept the child's state of deafness and acquire coping strategies in order to teach the child sign language as their mother tongue language that facilitates interaction with family and environment.

In Kenya both parents play an important role in the psychological well-being of adolescents and families, irrespective of the disabling condition. However, different pattern and strength of the relationships between family aspects and relationships are diverse (Abubakar, AlonsoArbiol, de-Vijver, Murugami, Arasa \& Mazrui, 2013). Both parental status and family functioning have an important and independent relationship to children's externalizing behaviors and psychological well-being (Thurman, Kidman, Nice \&Ikamari, 2015). Not much has been done to stress the role of family functioning aspects to help families to attain psychological well-being in families of children with hearing loss. It is on this background that this study explored how family functioning dimensions influence psychological wellbeing of parents raising hearing impaired children in Kericho County, Kenya.

\section{METHODS}

\section{Research Design}

The study adopted the survey research design. This design is flexible and easily accommodates a large number of participants within a short period of time. Likewise errors and weakness of one design that are likely to be introduced in the process of study are eliminated and integration of findings becomes the strength of the mixed methods design (Creswell \& Clark, 2011).

\section{Locale of the Study}

The study was carried out in Kericho County, Bureti and Londiani Sub-County. The Sub-counties have a 
population of $337,050(199,470$ and 137580 consecutively) (KNBS, 2019). Kericho is mainly an agricultural region and is the main administrative Centre for the County. This County was chosen because unlike many counties in Kenya which do not have any category of special schools in operation, Kericho County has two special primary schools with high population of learners with hearing impairments. The presence of these two institutions of children with hearing impairment (CWHI) implies, inevitability existence of children having hearing impairment residing within Kericho County.

On the other hand, although the schools are far apart, the geographical setting and road network serving between the two schools is improved such that accessibility is without any challenges. The objective of the study is also to include families from different backgrounds including ethnicity, socio-economic, rural, semi-urban or urban. The two schools accommodate children of mixed ethnicity and from different Counties of Kenya hence, offered the study the benefit of gathering enriched views from diverse nature of participants.

\section{Target Population}

The target population in this study were the children with hearing impairment from Kedowa and St. Kizitos Special Schools in Kericho County and their parents. Kedowa special school has enrolment of 162 while St. Kizitos has 192, comprising a total population of 354 . Therefore, the target population including their parents was 708 . For the purpose of the study, pupils were selected from class five to eight. The pupils from class five and above were selected because they have been in the school program long enough and have mastered the Sign Language, they are able to communicate and express their views clearly well compared to children in the lower classes. It was therefore expected that they would be able to express how they relate in their family and especially their parents.

\section{Sample Size and Sampling Procedures}

Fischer, (2017) describes a sample as a subcategory of the target population that the researcher intends to study with the aim of generalizing study results to target population. Likewise, Asiamah, Mensah, \&Oteng-Abayie (2017) refers a sample as a sub-set of items, elements or people carefully selected from the universe or total study population to form a representative portion for a study. A $10 \%$ sample size was obtained from each school. This is in line with Mugenda and Mugenda (2003) who hold that a sample of $10 \%$ is adequate for a large population of over fifty respondents.

The study applied purposive sampling where only special schools in Kericho County were considered for the study. The two schools were Kedowa and St. Kizitos. The sample size obtained is as shown in table 3.2. A stratified sampling technique and simple random sampling was used to select pupils from class five to eight and purposive random sampling was used to obtain parent-respondents of sampled pupils from each school. The table 3.3 shows the sample size from each school.

Table 1: Sample size per school

\begin{tabular}{|c|c|c|c|}
\hline Category & Children $(\mathrm{N})$ & $\begin{array}{c}\% \text { (Multiplier } \\
\text { Factor) }\end{array}$ & Sample Size \\
\hline Kedowa & 162 & 0.1 & 16 \\
\hline St. Kizitos & 192 & 0.1 & 19 \\
\hline Sub-Total & 354 & ---- & 35 \\
\hline Parents & 354 & ---- & 35 \\
\hline Grand Total & 708 & ----- & 70 \\
\hline
\end{tabular}

Description of Data Collection Instruments

The researcher used a standardized tool borrowed Rodriquez-Naranjo \& Cano, (2016). The researcher selected only the items that were deemed relevant to the study with modification and additional of items aimed at addressing specific research objectives. The questionnaires consists of 7 sections; Section A aimed at gathering demographic details such as, parent's gender, age, level of education, occupation and mode of communication, Section B dwelt on communication pattern in the family while Section C assessed a parent on affective responsiveness. Section D probed on problem-solving technics and section $\mathrm{E}$ was on behaviour control.

In section $\mathrm{F}$, the study aimed at exploring the Psychological Well-being of parents following Ryff and Keyes (1995) Scales of Psychological Well-Being. Although Ryff's inventory consists of either 84 question statement series reflecting the six areas of psychological well-being, namely the autonomy, environmental mastery, positive relations with others, personal growth, purpose in life, and self-acceptance. The current study selected the following 4 areas; self-acceptance, finding purpose in life, positive relationship in the family and environmental masterly according to the objectives of the study. Each area had 4 statements and choices on a Likert scale to choose an appropriate response on the extent to which they agree to the statement. Participants were provided with the questionnaire and guided through instructions in order to understand the format to select suitable response.

\section{RESULTS}

Family Communication Patterns and Parents Psychological well-being

The study sought to examine how family communication patterns influence the psychological wellbeing of parents raising children with hearing impairment. Five items of questionnaire were put in the Likert scale to determine communication pattern. Respondents were asked to rate communication patterns on a scale of 1 to 5 .

Where 1 represents "undecided," 2 represents "strongly disagree", 3 represents "disagree", 4 represents "agree" and 5 represents "strongly agree." The Mean, Standard Deviation 
and Variance were then computed for the variable as given in Table 2.

Table 2: Family Communication Patterns

\begin{tabular}{|c|c|c|c|c|}
\hline & $\mathrm{N}$ & Mean & $\begin{array}{c}\text { Std. } \\
\text { Deviation }\end{array}$ & Variance \\
\hline $\begin{array}{c}\text { I tell my child the } \\
\text { reason as to why I am } \\
\text { not happy with him/her }\end{array}$ & 35 & 2.66 & .938 & .879 \\
\hline $\begin{array}{c}\text { I understand the } \\
\text { feelings of my child } \\
\text { from what she/he } \\
\text { gestures }\end{array}$ & 35 & 3.14 & 1.033 & 1.067 \\
\hline $\begin{array}{c}\text { My child explains } \\
\text { his/her problems } \\
\text { instead of expressing } \\
\text { moods. }\end{array}$ & 35 & 2.97 & .954 & .911 \\
\hline $\begin{array}{c}\text { I tell my child when } \\
\text { she/he has done } \\
\text { something wrong }\end{array}$ & 35 & 3.29 & 1.045 & 1.092 \\
\hline $\begin{array}{c}\text { I keep quiet when I am } \\
\text { angry with my child }\end{array}$ & 35 & 3.14 & 1.264 & 1.597 \\
\hline & & & & \\
\hline
\end{tabular}

Parents were asked to indicate when they are not happy with their child with hearing impairment whether the child is told the reason; the data presented shows a mean of 2.66 meaning that the majority of the parents did not explain to their children why they were unhappy revealing an element of lack of communication. The statement whether parents understood the feelings of their children from the gestures that they made scored a mean of 3.14 implying that parents did not understand gestures from children with hearing impairment, which leads to ineffective communication between parents and CWHI.

The statement on whether children explained their problems or expressed mood, had responses that scored a mean of 2.97. This implies that, information from CWHI did not transmit sufficiently the intended message to their parents majorly because of the challenges involved in their way of interaction. The fact that the language CWHI used to express their problems did not relay their problem to be clearly understood points out a communication gap that needs to be improved. There is an indication that CWHI uses an alternative way of expressing their problems. The alternative methods chosen appear to complicate issues further rather than solving the problem.

\section{Affective responsiveness and psychological well-being of parents}

The study sought to determine the influence of affective responsiveness on psychological well-being of parents raising children with hearing impairment. To find out affective responsiveness of parents having children with hearing impairment, five items of questionnaire were put in the Likert scale. Respondents were asked to rate affective responsiveness on a scale of 1 to 5 . Where 1 represents undecided, 2 represents strongly disagree, 3 represents disagree, 4 represents agree and 5 represents strongly agree
The Mean, Standard Deviation and Variance were then computed for the variable as presented in table 3

Table 3: Affective responsiveness

\begin{tabular}{|c|c|c|c|c|}
\hline & $\mathrm{N}$ & Mean & $\begin{array}{c}\text { Std. } \\
\text { Deviati } \\
\text { on }\end{array}$ & Variance \\
\hline $\begin{array}{l}\text { I respond to my } \\
\text { child's emotional } \\
\text { needs without any } \\
\text { difficult }\end{array}$ & 35 & 3.89 & 1.231 & 1.516 \\
\hline $\begin{array}{l}\text { I am able to express } \\
\text { my love to my child } \\
\text { with hearing } \\
\text { impairment }\end{array}$ & 35 & 4.00 & 1.188 & 1.412 \\
\hline $\begin{array}{l}\text { I worry about my } \\
\text { child with hearing } \\
\text { impairment }\end{array}$ & 35 & 4.43 & .884 & .782 \\
\hline $\begin{array}{l}\text { My child with } \\
\text { hearing impairment } \\
\text { and I express } \\
\text { feelings for each } \\
\text { other. }\end{array}$ & 35 & 3.97 & 1.098 & 1.205 \\
\hline $\begin{array}{l}\text { I cry openly before } \\
\text { my child with } \\
\text { hearing impairment }\end{array}$ & 35 & 3.74 & 1.172 & 1.373 \\
\hline Valid N & 35 & & & \\
\hline
\end{tabular}

The parents were asked whether they respond to their CWHI emotionally without any difficult; the mean score for this statement was 3.89. This shows that as much as parents strive to respond to their children emotionally, it is difficult for them. Most parents agreed that they express love to their CWHI with a mean of 4.00 and a standard deviation of 1.188 . The statement on whether parents worry about their child with hearing impairment scored the highest mean at 4.43 with a standard deviation of .884, showing that the parents of CWHI are concerned about their children. The mean of 3.97 shows that majority parents are unable to share their love emotions with only a few parents being able to express the mutual feelings.

The implication here is that they have the feelings for each other but how to express these feelings could be a problem based on other underlying factors. The main hindrance concerns communication barrier due to lack of a common language that can help them express their feelings for each other with ease. The statement on parents crying openly scored the lowest mean at 3.74, meaning that majority parents hide their feelings and do not cry openly before their children. Normally, crying expresses negative emotions/feelings or pain that an individual may not be able to express verbally. Although parents of CHWI experience difficulties because of their children with HI, they do not express it before their children. If they ever cry because of their CWHI, possibly they do it secretly.

\section{Problem solving and psychological well-being of parents}

The study sought to determine the influence of family problem solving techniques on psychological wellbeing of parents raising children with hearing impairment. To find out the problem solving techniques used by parents 
having children with hearing impairment, five statements were constructed put in the Likert scale. To determine problem solving techniques, respondents were asked to rate problem solving techniques on a scale of 1 to 5 . Where1represents (undecided), 2 represents (strongly disagree), 3 represents (disagree), 4 represents (agree) and 5 represents (strongly agree). The Mean, Standard Deviation and Variance were then computed for the variable as presented in table 4.

Table 4: Problem Solving

\begin{tabular}{|c|c|c|c|c|}
\hline & $\mathrm{N}$ & Mean & $\begin{array}{c}\text { Std. } \\
\text { Deviati } \\
\text { on }\end{array}$ & Variance \\
\hline $\begin{array}{c}\text { I seek assistance to } \\
\text { solve most of the } \\
\text { daily problems } \\
\text { concerning my } \\
\text { child with hearing } \\
\text { impairment. }\end{array}$ & 35 & 2.66 & 1.056 & 1.114 \\
\hline $\begin{array}{c}\text { I always act on our } \\
\text { decisions regarding } \\
\text { problems with my } \\
\text { hearing impaired } \\
\text { child. }\end{array}$ & 35 & 3.23 & .910 & .829 \\
\hline $\begin{array}{c}\text { After family makes } \\
\text { a decision about a } \\
\text { problem, I always } \\
\text { discuss its success } \\
\text { or failure with my } \\
\text { hearing impaired } \\
\text { child. }\end{array}$ & 35 & 2.89 & .993 & .987 \\
\hline $\begin{array}{c}\text { I solve most } \\
\text { emotional issues } \\
\text { that come up with } \\
\text { my child with } \\
\text { hearing } \\
\text { impairment. }\end{array}$ & 35 & 3.00 & 1.057 & 1.118 \\
\hline $\begin{array}{c}\text { I always think of } \\
\text { different ways to } \\
\text { solve problems of } \\
\text { my child with } \\
\text { hearing } \\
\text { impairment. }\end{array}$ & 35 & 2.91 & 1.067 & \\
\hline
\end{tabular}

The parents were asked whether they sought assistance in solving most of the daily problems concerning their CWHI. The statement has a mean score of 2.22, which shows that they solved most of the problems on their own. On whether the parents acted on the decisions regarding problems with their CWHI, the mean score was 3.23, which means at times they did not take the agreed action. The statement on the involvement of CWHI on decisions making in the family has a mean of 2.89 which means they are hardly involved in the process of problem solving. About solving emotional issues with the CWHI, the mean of 3.00 means that their emotional issues are not solved together. Parents were asked whether they have alternative ways of solving the problems of their CWHI and this has a mean of 2.91 meaning that they have limited alternatives.

The research findings from questionnaires assessing problem-solving in family raising a child with hearing impairment and the influence on psychological well-being of parents, reported that; Majority parents do not seek assistance in solving most daily problems concerning their children with hearing impairments. This was indicated by several parents with a mean of 2.22 who sought assistance. Parents solved problems of children with hearing impairment on their own or failed to solve altogether. Likewise, many times (mean 3.23) parents do not act or inform the child with hearing impairment about decisions agreed in the family. While responding about emotional issues majority parents comprising a mean of 3.00 indicated that they do not solve children's emotional issues. Meaning most times children are left to manage situations on their own with only a few parents concerned about them.

Parents were asked whether they have alternative ways to solve problems of their children with hearing impairments in the family and though a high mean of 2.91 were positive that they use alternative ways, similarly a big group has limited alternatives. The feedback implies that parents undermine children's ability to make contributions to basic issues in the family. They are very controlling; they assume other peoples' responsibilities on themselves including making decisions about their lifestyles such as the type of communication to have in the family, medical care and education among others. These heighten their experience of stress resulting in psychological ailment.

\section{DISCUSSION}

Other studies on family communication and psychological wellbeing have reported varying trends. For Instance Zaidman-Zait, Most, Tarrasch, Haddad-eid, and Brand (2016) who assessed differences in parenting stress, personal acceptance of the child who is hearing-impaired, the parents' view of parenting self-efficacy, and the social (formal and informal social support) coping means between mothers and fathers of the deaf and hard-of-hearing $(\mathrm{D} / \mathrm{HH})$ among the Arabs. Findings revealed that, parenting the HI poses unique long-term challenges that can place the parents at greater levels of parenting stress. Adapting to challenges brought about by raising children with hearing impairment is determined by personal effort and the available social coping asset. The study further indicated that there is no significant difference between mothers and fathers regarding parenting stress, acceptance of the hearing impaired children or parental support systems.

Another study conducted by Brice and Strauss (2016) study in USA to review the factors that affect psychosocial adaptation of deaf children among the families established that shared communication system is crucial to avoid the sense of isolation among family members. It is common for parents to strive to find the suitable equal communication for their children. The findings further indicate that their efforts notwithstanding, some parents who have learnt some sign language still do not feel comfortable or find it easy enough to communicate well. However, what the deaf children ultimately use as sign or speech can have a big influence on their identity as a deaf people. Most commonly within the 
deaf community, a Signed Language is used to communicate. However, there are many deaf individuals who cannot sign. Good communication at home predicts better family relationship results.

The findings are in agreement with the MMFF model, which proposes four styles of communication namely: clear and direct, clear and indirect, masked and direct and masked and indirect. The responses from the children show that the type of communication used in the family is masked and indirect, yet Jobe-Shields, Buckholdt, Parra and Tillery, (2014) proposed clear and direct style as the best for a functioning family. The language is masked to the intended recipient due to the fact that they have not acquired the skill of unmasking communication. Most parents likewise use a language that is indirect to the recipient intended.

The field study findings addressing communication that exist in families raising children with hearing impairment, using questionnaires gathered that, majority parents do not have extensive interaction with their children not even explaining when they are unhappy with them. Interaction that exists between parent and child is superficial due to the fact that parents have not acquired sufficient skills for communication. Due to limited communication skills, parents are unable to understand most gestures that children use to communicate their feelings. Thus they are not in touch with the emotional feelings of their children. Children with hearing impairment also used moods as an alternative way to express themselves. The use of mood as a body language made communication more complex. Therefore parents explicitly expressed a great challenge in communication that affects effective interaction between them and their hearing impaired children.

Most parents have also not developed interest to know other ways of engaging to have a fulfilling conversation with their children with hearing loss. Therefore many times the children are lonely, unfairly accused by other siblings and are unjustly disciplined for offences they haven't committed. This happens because parents have not developed common language of interaction in the family where each one has room to express him/herself, be listened and understood.

Challenges in communication are realized to have great impact in the psychological well-being of both the child and parents. The repercussion bounces back to the family affecting other members, 'each element in the system is affected by whatever happens in any other element because of their interrelatedness (Epstein, Bishop, Lewis, 2009). Therefore any ailment of one member has influence in the entire family and every member is perceived as remedy to healing by supporting treatment in order to improve the situation.

The findings on affective responsiveness agree with the findings of Karaaslan et al., (2014) which sought to study responsive teaching with young Turkish children and their mothers; the findings indicated that some young children with disabilities have difficulties engaging in positive interpersonal relationships with their parents and other family members. In addition, Parents may also, at times, interrelate with these children in a manner that discourages social interaction. For example, they may be exceedingly authoritative and directive. Hence parents should learn how to apply situations that encourage relations and those that respond in positive ways.

This study is also in line with Pannilage (2017) who assessed the impact of family on children's Well-being and found that lack of parental love and care for their children negatively affects the children's well-being. The study further highlighted that less love and affection from parents had negative psychological effects on these children. Parenting behaviour and the quality of the parent-child relationships are critical in understanding and moulding children's well-being in families. Hence the impact of family affection and responsiveness to the children's wellbeing is significant. The study recommended the strengthening of the family in the society so as to facilitate significant positive influence on the well-being of the children.

Parents experience stressful circumstances pertaining the child with hearing impairment when there is little or no communication in the family that occur addressing factors that contribute to the adaptive functioning of the child with hearing impairment. And parents therefore, are at risk of experiencing decreased psychological well-being in the course of raising a child with hearing impairment. Lenders (2015) identifies affective responsiveness as a dimension in family functioning, which involves responding to different stimuli appropriately. The affective responsiveness can either be welfare emotions, which are positive or emergent emotions which are negative.

Despite missing affection from parents children acknowledge that they express concern towards them by the way they seem protective of them. Parents worry that other people may not be able to respond appropriately to the needs of their children with hearing impairment. They are also concerned about their safety that they may get knocked by a car/object and may not be able to communicate home to the parents. Parents are worried about finances to facilitate their education in the recommended special boarding schools which are usually expensive than regular schools. Parents are also bothered about their academic performance that it may not be satisfactory to attain supportive career to benefit them in the future. They are always concerned about what they will become and if they have the ability lead a "normal" family life like other hearing children.

The experience of lack of parental affection to the child could be contributed by limited interaction due to insufficient language of communication. Lack of communication in whatever form (oral/gestural) may give room to negative behaviour and individual interpretation not limiting misinterpretation that they are not loved, appreciated due to their disability. The child's behaviour based on his/her 
interpretation could have negative consequences on the psychological well-being of the parent.

It is for this purpose that the family systems theory supporting the study basis the emphasis on the fact that "when one family member experiences a psychological problem, treatment ought to be directed to the entire family instead of the symptomatic victim (Atwood, 2001; Skyttner, 2006). Unless therapeutic treatment is administered to the whole family, the vicious cycle of psychological distress will eventually spread to all members of the whole family because they are inter-related.

Problem solving was found to be in agreement with Davids (2016) who conducted a study in the rural areas of Western Cape, South Africa. The study sought to examine the relationship between parenting styles and decision making styles on healthy lifestyle behaviour of adolescents. Findings indicate that parenting strategies are associated with healthy lifestyle behaviours and decision making styles of their children, which impacts on the family and the well-being of the parents. The findings further showed that authoritative parenting, vigilant decision making styles and frequent engagement in healthy lifestyle behaviours were the most prevalent among families in the rural side of the Western Cape.

\section{CONCLUSION}

The study findings on dimensions measuring the family functioning, reported low levels of communication between the parents and the child, unsatisfactory emotional responsiveness to the expectation of the child, lack of child involvement in problem-solving in family and poor methods of behaviour control by parents. In communication a parents' insufficient skills to sustain adequate interaction with the hearing impaired child creates loophole in family functioning. The parent ought to acquire ways of communicating with the child instead of depending on instinctive and limited communication methods. Likewise poor methods of behaviour control, where parents were reported to be more controlling, directive, intrusive and too limiting to the child to explore the environment.

Most parents with hearing impaired children are psychologically stressed because of their inability to offer appropriate emotional response. If parents experience negativity of any kind he/she may not perform the parental role sufficiently. The negative effect torments him/her and the influence radiates to the family. Majority children with hearing impairment reported that parents minimally involve them in family problem solving. Parents deny them the opportunity of participating in decision-making that would otherwise enable them shapeup to achieve the desired behaviour or become the intended well-mannered child. By leaving them out implies they are less important or do not matter. Eventually a child with hearing impairment is condemned non-compliant, aggressive or rude.
It is unlikely for parents to adjust their life to suit the ways of the minority unique child's communication needs. The behaviour of remaining adamant therefore indicates a dysfunction and parents require to adopt interventional strategies to raise the family to functioning level which in turn improves a parents' psychological well-being. The MMFF model suggests that the negative psychological effects imparts beyond parents. It's experienced in every member in the family. Hence parents must embrace the strategies proposed in this study such as embracing the Sign Language communication to unlock the barriers involved. Parents also endeavour seeking support of a therapist in order to guide the family in coping, adapting with the unique child and recognising the resources in each member and become a healthy functioning family.

\section{ACKNOWLEDGEMENT}

The researcher is sincerely grateful and dearly appreciates all the participants and professionals in the study without whose support this study would not have been accomplished. I am most grateful to my readers for helping to shape the research.

\section{REFERENCES}

[1] Abubakar, A. Alonso, A., I., Vijver, F., Murugami, Arasa, J.N., \& Mazrui, L. (2013). Attachment and Psychological Well-being among Adolescents with and Without Disabilities in Kenya: The Mediating Role of Identity Formation. Journal of Adolescence 36(5):849-57. DOI: 10.1016/j. adolescence.

[2] Atwood, J., D., (2001). Family Systems/Family Therapy: Application for clinical practice. Binghamton, NY: The Haworth Press, Inc.

[3] Brice. P. \& Strauss. G. (2016). Deaf adolescents in a hearing world: A review of factors affecting psychosocial adaptation. Adolescent Health, Medicine and Therapeutics, 7, 67-76. DOI; https://doi.org/10.2147/AHMT.S60261

[4] Briffa, D., Davidson, F., \& Ferndale. M. D. (2016). An identification of the social and emotional needs of people living with post-lingual hearing loss. JADARA, 50(2), 67-88. Childhood Hearing Loss on the Family: Mothers' and Fathers' Stress and Coping Resources. The Journal of Deaf Studies and Deaf Education, 21(1), 23-33.

[5] Cole, E. B., \& Flexer, C. (2019).Children with hearing loss: Developing listening and talking, birth to six. Plural Publishing.

[6] Creswell, J W., and Vicki L. Plano Clark (2007). Designing and Conducting Mixed Methods Research. Thousand Oaks, CA: Sage Publications.

[7] Creswell, J. W., \& Plano Clark, V. L. (2011). Designing and Conducting mixed method Research (2nd ed.). Thousand Oaks, CA: Sage.

[8] Davids, E.L. (2016). A model examining the relationship between parenting styles and decision making styles on healthy lifestyle behaviour of adolescents in the rural Western Cape. (PhD Dissertation, University of the Western Cape).

[9] Davids, E.L., \& Roman, N. (2013). Does family structure matter? Comparing the life goals and aspirations of learners in secondary schools. South African Journal of Education, 33(3), 1-12. http://dx.doi.org/10.15700/201503070745.

[10] Davids, E.L., Roman, N. V., \& Leach, L. (2015). The effect of family structure on decision-making, parenting styles and healthy lifestyle behaviour of adolescents in rural South Africa. African Journal of Physical, Health Education, Recreation and Dance, 21(3:2), 953-967.

[11] Davids, J. L., Ryan, J. Yassin, Z., Hendrickse, S. \& Roman, N., V., (2016). Family structure and functioning: Influences on 
adolescents psychological needs, goals and aspirations in a South African setting. Journal of Psychology in Africa, 26(4), 351-356. Disabilities in Kenya: The Mediating Role of Identity Formation. Journal of Adolescence 36(5):849-57. DOI: 10.1016/j. adolescence.

[12] Dyson, L. (2010). Unanticipated effects of children with learning disabilities on their families. Learning Disability Quarterly, 33(4), 43-55.

[13] Epistein, N. B., Bishop, D.S., \& Levin, S. (2009). The McMaster Model of Family Functioning.Journal of Marital and Family Theory. 4(4) 19-31.

[14] Harrison, M., Page, T., A., Oleson, J., Spratford M., Unflat Berry, L., et, al (2015). Factors affecting Early Services for Children who are hard of hearing. Journal of Language, Speech and hearing Services in schools.

[15] Humphries, T., Smith, S., (2019). Support for Parents of Deaf Children: Common questions and informed, evidence-based answers. International Journal of paediatric Otorhinolaryngology, $118,134-142$

[16] Karaaslan, O., Diken, I.H., \& Mahoney, G. (2013). A Randomized Control Study of Responsive Teaching with Young Turkish Children and Their Mothers. Topics in Early Childhood Special Education, 33(1), 18-27.

[17] KNBS, (2019). Kenya Population and Housing Census. Volume 1: Population by County and Sub-County. Nairobi. Kenya National Bureau of statistics.

[18] Kuhlthau, K., Kahn, R., Hill, K. S., Gnanasekaran, S., \& Ettner, S L. (2010). The well-being of parental caregivers of children with activity limitations. MCH 14, 155-163. doi: 10.1007/s10995-0080434-1

[19] Lenders, S. R. (2015). The role of family functioning in the decision-making styles of adolescents in the Overberg area. Psychology 2015.

[20] Moeller, M.P., White. R., \& Shisler, L., (2006). Primary care physicians' knowledge, attitudes and practices related to new born hearing screening. Paediatrics.118, 1357-70
[21] Mweri, J. G, (2019). Why new parents of deaf children also have to learn to cope emotionally with the knowledge that their baby is deaf. Health Pol 2(1)14-16.

[22] Pozo, P., Sarriá, E., \& Brioso, A. (2013). Family quality of life and psychological well-being in Parents of children with autism spectrum disorders: A double ABCX model. (Online). https://doi.org/10.1111/jir.12042

[23] Ryff, C. D., \& Keyes, C. L. M. (1995). The structure of psychological well-being revisited. Journal of Personality and Social Psychology, 69(4), 719-727.

[24] Sola, C., Lopez, L., Padilla, G., Daza, M. \& Aguilar-Parra. J.M. (2016) Subjective Psychological Well-Being in Families with Blind Children: How Can We Improve It? Psychology. 7,487.doi: 10.3389/fpsyg.2016.00487

[25] Stanescu, D.F., \& Romer, G. (2011). Family Functioning and Adolescents' Psychological Well-Being in Families with a TBI parent. Psychology 2(7) 681-686.

[26] Seligman, M., Darling, R.B., (2007). Ordinary Families, Special Children: a systems approach to Childhood with Disability ( $3^{\text {rd }}$ ed.). New York: Guilford Press.

[27] Thurman, T. R., Kidman, R., \& Taylor, T. M. (2015). Does investment in home visitors lead to better psychological health for HIV-affected families? Results from a quasi-experimental evaluation in South Africa. AIDS care, 26(1), 2-10.

[28] Zaidman-Zait, A., Most, T., Tarrasch, R., Haddad-eid, E., \& Brand, D. (2016). The Impact of Childhood Hearing Loss on the Family: Mothers' and Fathers' Stress and Coping Resources. The Journal of Deaf Studies and Deaf Education, 21(1), 23-33.

[29] Zaidman-Zait, A. \& Poon, B., T. (2014) Social Support for Parents of deaf Children: Moving toward contextualized understanding. Journal of deaf studies and deaf education, 19(2), 176-188.

[30] Zwane, C., Venter, C., Temane, M. Q., \& Chigeza, S. (2012). Black adults' perceptions of healthy family functioning. Journal of Psychology in Africa, 22(1), 43-48. 